\title{
Identification of Cucumis Sativus Urease as a Potential Urea Binding Enzyme by Computational Methods
}

\author{
Vinod Kumar Yata ${ }^{1 \mathbb{D}}$, Akash Deep Biswas ${ }^{2,3} \mathbb{( D}^{\mathbb{D}}$, Ankita Deb ${ }^{4(\mathbb{D})}$, Airy Sanjeev ${ }^{4}$, Venkata Satish \\ Kumar Mattaparthi ${ }^{4, *(D)}$


Tezpur, Assam, 784028, India; ankita.deb12@gmail.com (A.D.); airy.sanjeev01@gmail.com (A.S.); mvenkatasatishkumar@gmail.com, venkata@tezu.ernet.in (V.S.K.M.); \\ 4 Molecular Modeling and Simulation Laboratory, Department of Molecular Biology and Biotechnology, Tezpur University, \\ * Correspondence: mvenkatasatishkumar@gmail.com, venkata@tezu.ernet.in;
}

Scopus Author ID 54962670000

Received: 27.07.2020; Revised: 28.08.2020; Accepted: 30.08.2020; Published: 2.09.2020

\begin{abstract}
Urea is the most commonly used solid nitrogenous fertilizer owing to the fact that it contains high nitrogen content and also plays a significant role in the growth of plants. Many plant ureases catalyze the conversion of urea to ammonia and carbon dioxide. Identification of high-affinity plant ureases is considered to be one of the burning topics among several researchers for the development of Genetically Modified (GMO) crops. In the current study, the binding affinity of urea was compared with some of the plant ureases. In regard to this Pigeon pea Urease (PpU) was fixed as a reference to predict the binding pocket and thereby compare the binding affinity with urea. Cucumis sativus Urease $(\mathrm{CsU})$ and Fragaria vesca Urease (FvU) were screened for comparison. Performing Molecular Dynamics (MD) simulation, molecular docking, and binding free energy calculation, it was observed that the structure of $\mathrm{CsU}$ was relatively stable and had a greater affinity of $-3.37 \mathrm{kcal} / \mathrm{mol}$ with urea when compared with PpU and FvU. Predominantly, we report here that comparatively, CsU is a potential urea binding enzyme. Our findings in this study would be a useful tool in engineering novel high-affinity plant ureases drugs.
\end{abstract}

Keywords: Urea; Ureases; Molecular Dynamics; Molecular Docking; MM-PBSA; MM-GBSA; Pigeon pea Urease; Cucumis sativus Urease; Fragaria vesca Urease; Binding Free Energy.

(c) 2020 by the authors. This article is an open-access article distributed under the terms and conditions of the Creative Commons Attribution (CC BY) license (https://creativecommons.org/licenses/by/4.0/).

\section{Introduction}

The study on ureases extract from plant sources has acquired greater importance in the environmental, agricultural, and clinical sciences [1-4]. As nitrogen is evidently considered to be one of the essential elements for the plant growth, [5, 6] ureases play a substantial role in providing nitrogen to the plants through urea break down [7, 8]. Besides, urea is one of the essential fertilizers for the cultivation of major food crops $[9,10]$, and engineering of highaffinity urease enzymes would enable the development of transgenic plants [11], which could utilize high amounts of urea and greatly reduce the unutilized urea for field cultivation. Furthermore, unutilized urea has been a threat to the environment as it releases abnormal amounts of ammonia into the atmosphere. Above and beyond this, there is a great demand for the development of high-affinity urease in the clinical research field $[12,13]$ as this would 
increase the sensitivity of urea detection from blood samples. As a result, quantitative structure and activity relationship (QSAR) studies of plant ureases are essential for the assessment of urea binding efficiency. Engineering novel ureases by computational methods could lead to the development of environment-friendly GMO crops.

In order to identify high-affinity plant ureases, the crystallized structure of $\mathrm{PpU}$ was considered as a reference urease. As mutations in a protein sequence may alter its affinity towards the ligand urea, as computational analysis of mutant hotspots helps in the identification of similar sequences with mutant sites from the protein sequence databases, we screened the plant ureases based on hotspot mutant. In the present investigation, we had selected two plant ureases $\mathrm{CsU}$ and $\mathrm{FvU}$ from the protein sequence database based on the output generated from BLAST [14] and mutant hotspots of PpU. Due to the unavailability of the crystallized structures, I-TASSER [15] online server was used for modeling. In order to characterize and study the molecular interactions with urea, we docked urea with the three structures of ureases using AutoDock 4.2 (AD) [16]. The stability and the dynamics of the ureases (PpU and CsU) in the presence and absence of urea were studied using MD simulation. The relative binding free energy of PpU-urea and CsU-urea complexes were also determined and compared using MM-GBSA/PBSA methods [17]. CsU was found out to have the best binding affinity among the others.

\section{Materials and Methods}

\subsection{Identification of possible mutants of $P p U$.}

The crystalized 3-D structure of PpU having PDB ID: 4G7E [18] was considered from the Protein Data Bank. In order to analyze the Wild Type (WT) structure, we identified the mutagenesis hot spots of PpU using Hotspot Wizard Server [19,20].

\subsection{Identification of mutated protein sequences and protein modeling:}

To identify the mutated protein sequences of $\mathrm{PpU}$, the amino acid sequence of $\mathrm{PpU}$ was submitted onto the BLAST server, and the output obtained was checked for the presence of different amino acids corresponding to the results obtained using Hotspot wizard. In pursuit of these sequences of FvU with accession number XP_004310053.1 and CsU with accession number XP_004135306.1 were selected for structure modeling. Alignment of sequences PpU, $\mathrm{CsU}$, and FvU were done using CLUSTAL Omega multiple sequence alignment tool [21] in order to cross-check the hotspots mutation sites of $\mathrm{PpU}$. The amino acid sequence of $\mathrm{CsU}$ and FvU was submitted to I-TASSER server [22] to model the structures. This server is known for predicting the protein structure based on the sequence-to-structure-to-function paradigm. Using PROCHECK, the resultant 3D model structure of CsU and FvU were then evaluated for stereochemical quality by analyzing residue-by-residue geometry and overall structure geometry [23]. The sequence similarities between the three proteins are shown using ESPript 3.

\subsection{Binding site analysis.}

To determine the favorable binding site for urea, 46 bounded urea proteins were extracted from Protein Data Bank [24]. The sequence of 46 urea- bound proteins and the PpU were then subjected to multiple sequence alignment using CLUSTAL Omega. Using bioinformatics tools of EMBL-EBI [25] phylogenetic tree was constructed with the help of 
data provided by CLUSTAL Omega, which were depicted in the form of alignment results. Analysis of the urea binding sites was carried out with the help of PDBsum, [26] accompanied by their closely related protein structures. Using the Smith-Waterman Local Alignment algorithm [27], three protein structures for the prediction of binding sites of PpU were selected.

\subsection{Docking.}

Using AD [28-30], urea as a ligand, it was docked with PpU, CsU \& FvU. Water molecules were removed for the preparation of the docking structure [31,32]. Using the prepare_receptor4.py script from MGL Tools [33], charges and non-polar hydrogen atoms were added. [34, 35] The default values were used for the docking parameters in AD. However, the numbers of AD Generic Algorithm (GA) runs were increased from 10 to 1000, and the grid spacing changed from 0.375 to 0.5 . The search box was large enough to cover the active site of the protein structure. The 1000 independent GA runs from AD were processed using the built-in clustering analysis with a $2.0 \AA$ cut-off. The overall best pose was chosen based on the factors which emphasize the binding affinity, the best pose of PpU, CsU, and FvU, which have the significant characteristics of binding affinity, and further MD studies were carried out related to this content.

\subsection{Molecular dynamics simulation methods.}

MD simulation was carried out on the structures of $\mathrm{PpU}, \mathrm{CsU}$, with and without the urea complexes, respectively. The initial crystal structure of PpU was extracted from the PDB, and in pursuit of this, the complex structure of $\mathrm{PpU}$ with ligand molecule, urea as was obtained from the docking method. The initial model structure of CsU was obtained from ITASSER, and the complex structure of the same with urea was built using AD. All the four systems were subjected to MD simulation using the Sander module of AMBER [36] software package with the ff99SB Amber force field [37]. Using Leap and antechamber module in the initial coordinate and topology files for the four systems were acquired. In each case of the system, the resultant initial structure was explicitly solvated using TIP3P water model [38] in a box large enough to enclose the whole proteins. The structure was then subjected to minimization with 1000 steps of steepest descent followed by 2000 steps of the conjugate gradient. The harmonic constraints were used by fixing the protein molecule with force constant of 500 $\mathrm{kcal} / \mathrm{mol} / \AA^{2}$, to remove the bad contacts between water molecules and the solute. The minimized structure was then equilibrated with $40 \mathrm{ps}$ of MD run with a time step of $2 \mathrm{fs}$. During the MD simulation, the system was gradually heated up from 0 to $300 \mathrm{~K}$ using weak harmonic constraints of $20 \mathrm{kcal} / \mathrm{mol} / \AA^{2}$ on the solute to its initial structure, which allows the structure to undergo slow relaxation. In addition, SHAKE constraints [39] using a geometrical tolerance of $5 \times 10^{-4} \AA$ was imposed on all covalent bonds involving hydrogen atoms. Later, the MD run was performed at NPT using the Berendsen weak coupling method for the temperature regulation [40] ( $0.5 \mathrm{ps}$ time constant for heat bath coupling and 0.2 ps pressure relaxation time). After this, we have carried out additional 5000 steps of conjugate gradient energy minimization while decreasing the force constant of the harmonic restraints gradually from $20 \mathrm{kcal} / \mathrm{mol} / \AA^{2}$ to zero in steps of $5 \mathrm{kcal} / \mathrm{mol} / \AA^{2}$. Finally, for structural analysis and its properties, we carried out $10 \mathrm{~ns}$ long NVT MD using a heat bath coupling time constant of 1 ps for PsU and CsU, whereas $8 \mathrm{~ns}$ long NVT simulation for the PsU, CsU with the urea complexes. The analysis of 
structural parameters like RMSD, B factor values are interpreted applying the ptraj module of AMBER package.

\subsection{MM-GBSA/PBSA calculations of PpU/CsU-urea complexes.}

To determine the relative binding free energy of PpU/CsU-urea complexes, we used the MM-GBSA/PBSA method. For the MM-PBSA calculations, we extracted the snapshots of the complex system (without water and ions) from our MD production run. Then GBSA/PBSA analysis was performed on the three components of each of the complex systems: the protein urease (CsU/PpU), ligand (urea), and the complex (CsU/PpU-urea). For each of these components, the interaction energies and solvation free energies were calculated, and the average results were obtained to estimate the binding free energy. The binding free energy of the $\mathrm{PpU}$ and $\mathrm{CsU}$ in complex with urea was calculated by the formula:

$$
\Delta \mathrm{G}_{\text {bind }}=G_{\text {tot }}(P p U, C s U-\text { urea complex })-G_{\text {tot }}(P p U, C s U)-G_{t o t}(\text { urea })
$$

In MM-GBSA calculations, we have used the pairwise GB model with parameters described by Tsui and Case [35]. For all other settings, we have used the default values. While in the MM-PBSA calculations, we set the internal dielectric constant and external one as 1.0 and 80.0 , respectively.

\section{Results and Discussion}

\subsection{Secondary structure analysis of PpU.}

The crystal structure of PpU has been solved with PDB ID: 4G7E, and it could conceivably be used as an experimental and reference structure for studying other ureases whose crystal structure has not been solved yet. The crystal structure of PpU contains two chains (A \& B), and each chain consists of 840 amino acids. It can also be seen that both the chain sequences are $99 \%$ identical, but a single mismatching in the amino acid residue (Met in place of Cys) between chain A and B at position'207' was observed. The 3D structural representation of PpU obtained using UCSF chimera [41] was shown in Figure S1.

\subsection{Mutation sites of pigeon pea urease.}

The five possible mutable hotspot residues of PpU obtained from Hotspot Wizard Server, out of which three hotspots are in chain B, and two hotspots are in chain A shown in Table1. The hotspots were sequenced on the basis of their mutability score that ranges from 9 to 6 . The chances of introducing various amino acids at a particular position in the protein chain increase with the mutability score. Met at 487 positions in chain B is located in the catalytic pocket and is highly mutable with a mutability score of 9 .

Table 1. Mutability scores for amino acids of PpU structure by hotspot wizard.

\begin{tabular}{l|l|l|l} 
Chain & Amino Acid & Flags* & Mutability Score** \\
\hline B & Met 487 & -- T & 9 \\
\hline B & Arg 439 & - P- & 8 \\
\hline A & Arg 439 & -PT & 8 \\
\hline B & Ile 582 & -- T & 7 \\
\hline A & Ile 630 & -- T & 6
\end{tabular}

Note: *Flags: Information about catalytic residue $(\mathrm{C})$, residues forming walls of the active site pocket $(\mathrm{P})$, or a tunnel (T). **Mutability Score (9 - High mutability, 1 - Low mutability). 
Arg at 439 of chain A is located in both tunnels as well as in the catalytic pocket of protein, whereas in chain $B$ the same residue is located in the catalytic pocket site and has the same mutability score of 8 . Ile at 582 of chain B and 630 of chain A has a mutability score of 7 and 6, respectively, that are present in the tunnel of protein. Arg at 439 positions of chain B is the most mutable, whereas Ile at 630 positions of chain $\mathrm{A}$ is the least mutable, shown in Table 1 and in Figure S1.

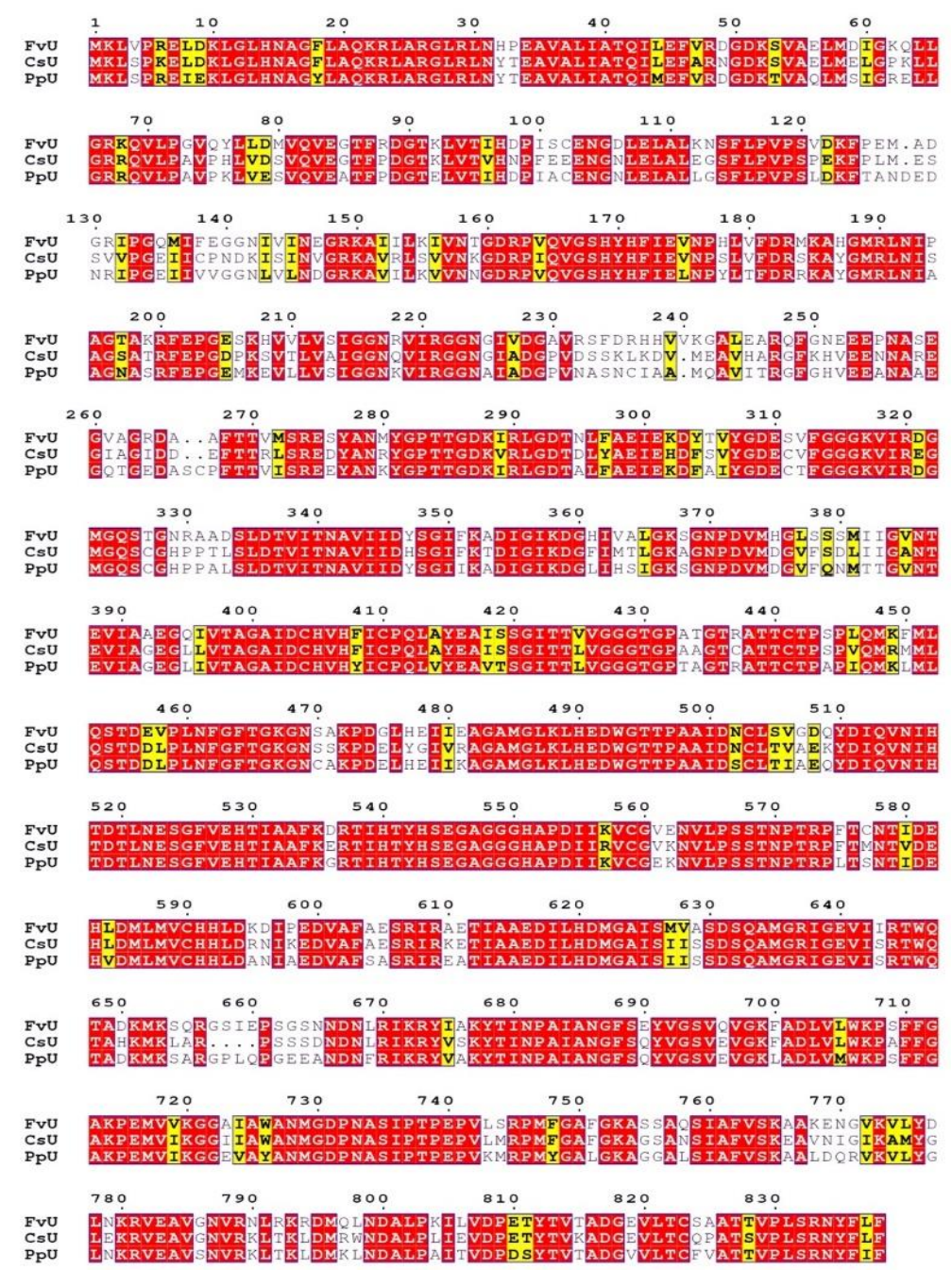

Figure 1. Multiple sequence alignment of PpU with models - The protein with PDB ID 4G7E is a PpU CsU with the accession number XP_004310053.1 \& FvU with the accession number XP_004135306.1.

\subsection{Identification of mutated protein sequences and protein modeling.}

Replacement of amino acids at specific positions in the protein sequence was considered to be one of the probable reasons for the change in the activity of the protein [42]. In consideration of the selection of similar protein, sequences based on the hotspot mutations as a reasonable choice for modeling and computational analysis were examined. In our study, two protein sequences were selected from the BLAST output of PpU for protein modeling. The first sequence taken from $\mathrm{CsU}$ is $78 \%$ identical to that of $\mathrm{PpU}$ that shows an alignment of one mutated site with respect to $\mathrm{PpU}$ at Arg439 position. At this specific position, Arg is replaced with Cys in CsU (Figure S2). The second sequence is of FvU, which is $77 \%$ identical to PpU in that the alignment is of one mutated site with respect to $\mathrm{PpU}$ at the Ile630 position. In this case, Ile is replaced at a specified position with Val in FvU (Figure S3). Multiple sequence alignment of these three ureases were used to verify the result obtained from BLAST, and from 
their interpretation, residues at the appropriate sites were observed, which were merely at the same site, shown in Figure 1. Secondary structure analyses of the two sequences were obtained from the model structure built using I-TASSER server. Using the Ramachandran plot, the modeled structure retrieved from I-TASSER portal was validated, which showed a considerable good stereochemical quality (Figure S4 and Figure S5).

\subsection{Prediction of urea binding sites of $P p U$.}

A new paradigm for binding site analysis was adopted in our study, which emphasizes the Binding site information that was obtained from the urea bound protein sequences available in the PDB. Based on molecular phylogenetic analysis [43] 10 protein sequences that are closely related to PpU were selected (Figures S6) from 46 urea bound protein sequences available in PDB. The selected 10 protein sequences were analyzed for their urea binding sites by PDBSum and further checked for the local alignment [44] with PpU. From the local alignment result, three protein sequences were selected (PDB ID 3P06 (Chain A) and 1EP5 (Chain A\& B). The interactive residues present in these three protein sequences were identified from LigPlot (Supporting Figure S7 \& Table S1).

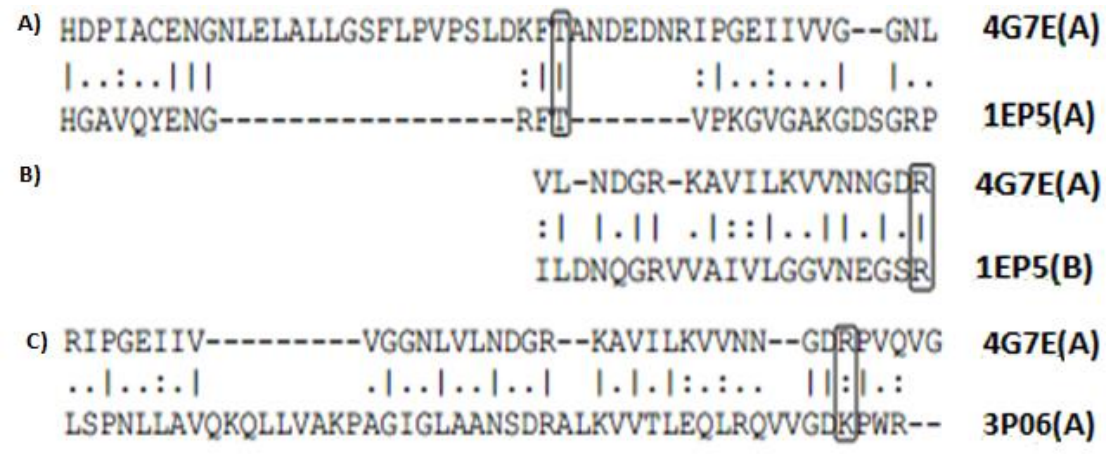

Figure 2. Local alignments of $\mathrm{PpU}$ with urea-bound protein, residues constrained in rectangles are sites identified using LIGPLOT: (a) At 125 position of $\mathrm{PpU}$ and capsid protein $\mathrm{C}$ have the same residue, which is Threonine (b) At 163 position of $\mathrm{PpU}$ and capsid protein $\mathrm{C}$ have the same residue, which is Arginine (c) At 163 position of PpU, VP4 protein and urease have different but alike amino acids, that are Lysine and Arginine respectively.

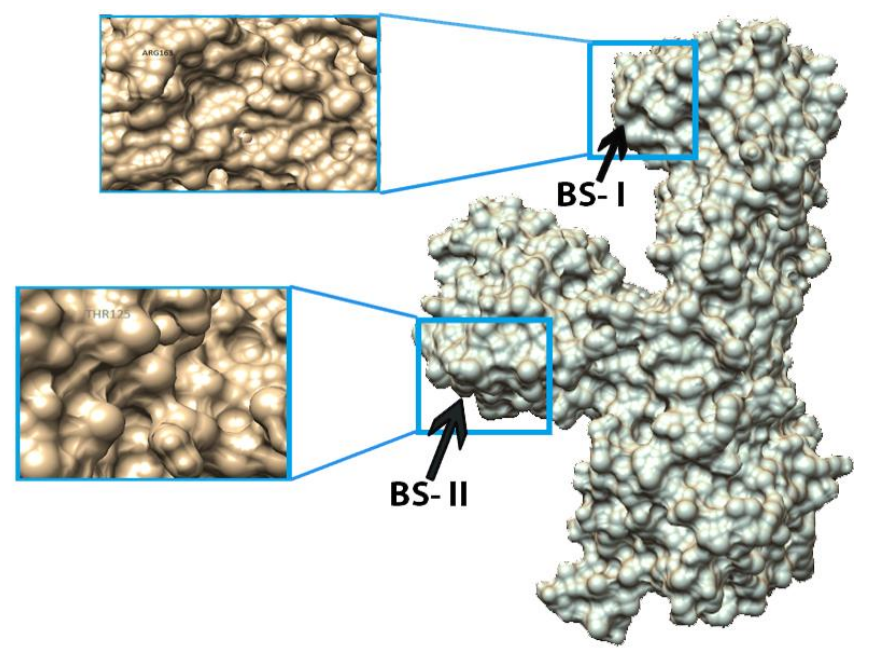

Figure 3. Binding sites of PpU, Binding site I contain grove around Arg163 amino acid molecule, and Binding site II contain grove around Thr125 amino acid molecule.

Local alignment of these three protein sequences along with $\mathrm{PpU}$ sequence confirmed the urea binding residues present in PpU. In 1EP5 (Chain A), the interactive residue with urea 
ligand was found to be Thr264 (Figure 2a), whereas in (Chain B), $\operatorname{Arg} 250$ was found to be the interactive residue with urea which matches Arg163 of PpU (Figure 2b). In 3P06, Lys812 was found to be the interacting residue with urea that matches with chemically similar residue Arg163 of PpU (Figure 2c). For the docking procedure, both the binding sites were considered, which were visualized and studied with the help of chimera (Figure 3). The binding pocket at residue Arg163 is termed as Binding site I (BS I), and that of residue Thr125 is termed as Binding site II (BS II).

\subsection{Docking.}

The urea molecules at both the binding sites of $\mathrm{PpU}$ were docked with regard to find out the lowest energy binding site for further docking analysis. BS-I is found to be the better binding site than BS-II with a binding energy of $-2.71 \mathrm{kcal} / \mathrm{mol}$. In pursuit of protein and ligand preparation, the grid box was built around BS-I in PpU and docked with urea (Figure 4a \& Figure 5a).

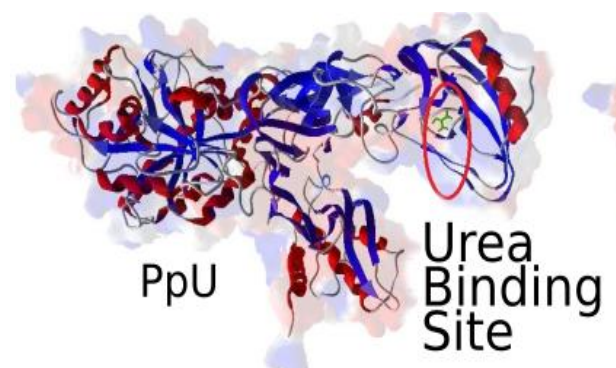

(a)

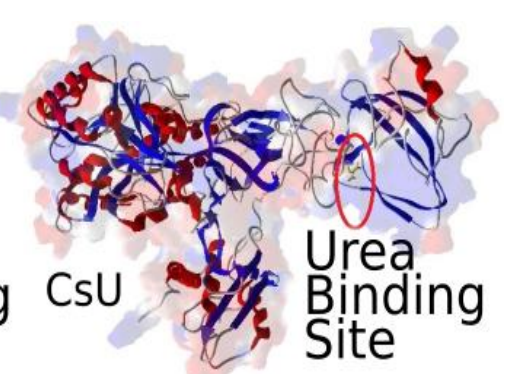

(b)

Figure 4. (a) Binding of urea with $\mathrm{PpU}$ in its binding site. (b) Binding of urea with CsU.

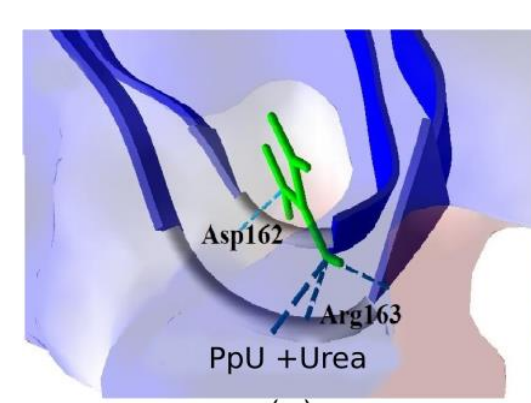

(a)



(b)

Figure 5. (a) Interaction profiles of residues involved in binding of urea with $\mathrm{PpU}$ in its binding site. (b) Interaction profiles of residues involved in binding of urea with $\mathrm{CsU}$.

Table 2. Binding energy obtained after docking of a protein molecule.

\begin{tabular}{|c|c|c|c|c|c|c|}
\hline \multirow[t]{2}{*}{ Sl. No. } & \multirow[t]{2}{*}{ Protein Name } & \multirow[t]{2}{*}{$\begin{array}{l}\text { Binding Energy } \\
\text { (kcal/mol) }\end{array}$} & \multicolumn{2}{|c|}{ Interaction Details } & \multirow[t]{2}{*}{$\begin{array}{l}\text { Urea } \\
\text { Atom }\end{array}$} & \multirow[t]{2}{*}{$\begin{array}{l}\text { Distance } \\
(\AA)\end{array}$} \\
\hline & & & $\mathbf{A A}^{1}$ & Position & & \\
\hline \multirow{4}{*}{1} & \multirow{4}{*}{ Pigeon pea Urease } & \multirow{4}{*}{-2.71} & Asp & $162(\mathrm{HN})$ & $\mathrm{O} 1$ & 1.922 \\
\hline & & & Arg & $163(\mathrm{HE})$ & $\mathrm{O} 1$ & 2.122 \\
\hline & & & Arg & $163(\mathrm{O})$ & H3 & 2.035 \\
\hline & & & Arg & $163(\mathrm{HH} 21)$ & $\mathrm{O} 1$ & 2.229 \\
\hline \multirow{4}{*}{2} & \multirow{4}{*}{$\begin{array}{l}\text { Cucumis sativus } \\
\text { Urease }\end{array}$} & \multirow{4}{*}{-3.37} & Arg & $162(\mathrm{O})$ & $\mathrm{H} 4$ & 1.849 \\
\hline & & & Asn & 158 (HD21) & $\mathrm{O} 1$ & 1.749 \\
\hline & & & Gly & $160(\mathrm{HN})$ & O1 & 2.108 \\
\hline & & & Arg & $162(\mathrm{O})$ & H1 & 1.708 \\
\hline \multirow{2}{*}{3} & \multirow{2}{*}{$\begin{array}{l}\text { Fragaria vesca } \\
\text { urease }\end{array}$} & \multirow{2}{*}{-2.42} & Pro & $163(\mathrm{O})$ & $\mathrm{H} 4$ & 2.162 \\
\hline & & & Arg & $162(\mathrm{HE})$ & $\mathrm{O} 1$ & 1.972 \\
\hline
\end{tabular}

Note: 1 AA: Amino Acid 
Similar binding site locations were selected for the $\mathrm{CsU}$ (Figure $4 \mathrm{~b} \&$ Figure $5 \mathrm{~b}$ ) and FvU for the preparation of the grid box and further docked with urea. After docking the interpretation of these complexes, the binding energy was calculated using MGL Tools from which it was noticed that $\mathrm{CsU}$ has the lowest binding energy of $-3.37 \mathrm{kcal} / \mathrm{mol}$ (Table 2), which indicates a high affinity towards the urea molecule. The possible reason for the high affinity of $\mathrm{CsU}$ for urea is due to the replacement of residue Cys in place of Arg439 in PpU. While in the case of FvU the binding energy calculation was found out to be higher due to the replacement of Val in the place of Ile63 in PpU.

\subsection{Molecular dynamics simulation results.}

In order to compare the salient structural features of the reference PpU and the other considered plant urease (CsU), MD simulation was carried out, which showed the following features:

\subsubsection{RMSD analysis.}

The conformational stability of ureases ( $\mathrm{PpU} \& \mathrm{CsU}$ ) in the presence (Figure 6a) and absence of urea as a ligand has been studied (Figure 6b). From these figures, it was noticed that the complex form of CsU was equally stable with the complex form of PpU. The RMSD value for both the complex structure settles well below $3 \AA$, but in the absence of the ligand urea, the structure of $\mathrm{CsU}$ is not relatively stable with comparison to $\mathrm{PpU}$ structure.

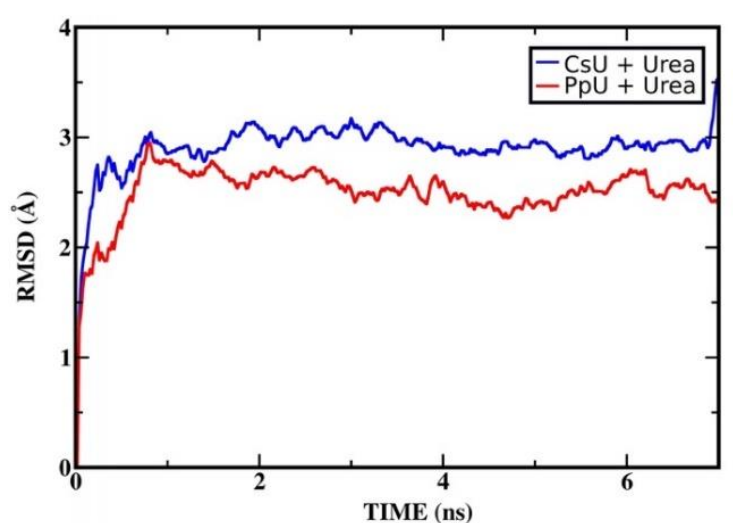

(a)

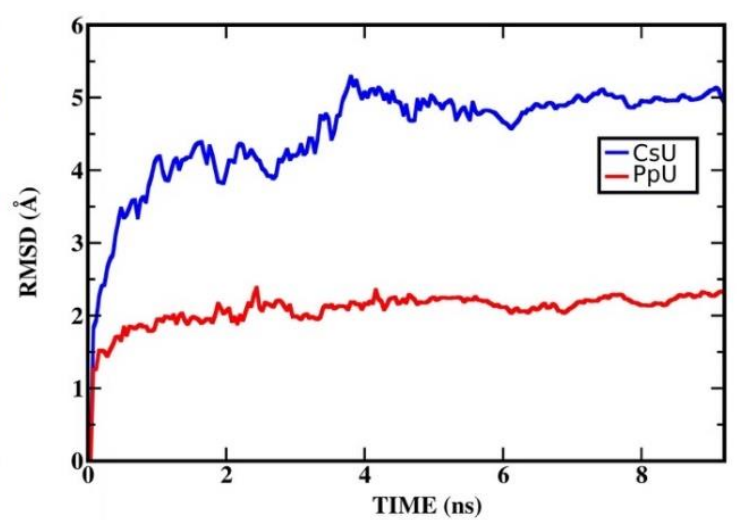

(b)

Figure 6. (a) Backbone RMSD vs Time period of simulation period for the CsU protein and PpU protein complexed with urea. (b) Backbone RMSD vs. Time period of simulation period for the CsU protein and PpU protein without urea.

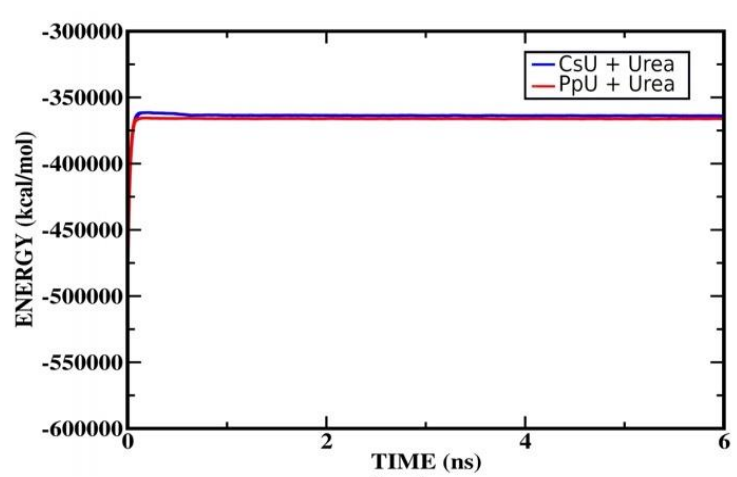

(a)

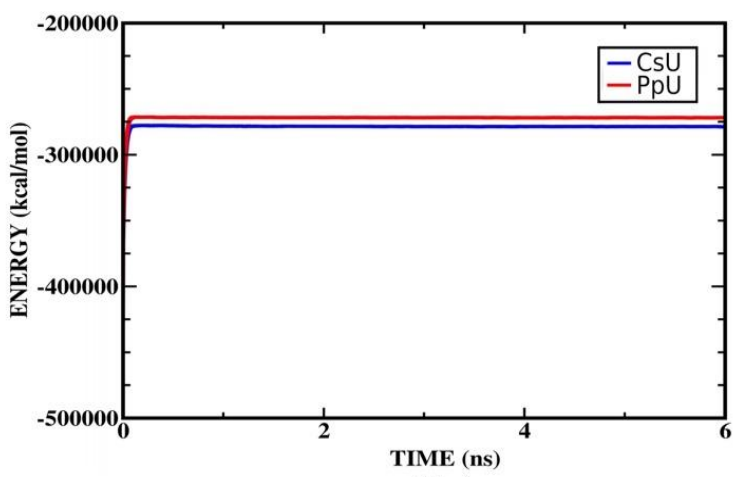

(b)

Figure 7. (a) Total Energy vs Time period of MD simulation for CsU protein and PpU protein with urea. (b) Total Energy vs. Time period of simulation for $\mathrm{CsU}$ protein and $\mathrm{PpU}$ protein without urea. 


\subsubsection{Total energy of the system.}

The stability of the structure in terms of the total energy of the system, which depicts the total energy as a function of time of the simulation for both $\mathrm{CsU}$ and $\mathrm{PpU}$ in the presence and absence of urea is shown in Figure $7 \mathrm{a}$ and Figure $7 \mathrm{~b}$, clearly shows that the complexed form of both $\mathrm{CsU}$ and $\mathrm{PpU}$ exhibits almost equivalent total energy values while in the absence of the ligand urea, $\mathrm{PpU}$ is relatively more stable than the $\mathrm{CsU}$.

\subsubsection{Radius of gyration analysis.}

The radius of gyration analysis for both the ureases: $\mathrm{CsU}$ and $\mathrm{PpU}$ were carried out to observe the compactness and size of the protein structure during the course of the simulation. In this analysis (Figure $8 \mathrm{a} \& \mathrm{~b}$ ), the complex of $\mathrm{CsU}$ and $\mathrm{PpU}$ showed the nearly same trend in the radius of gyration $(\mathrm{Rg})$ values, but they exhibit different radius of gyration profile in the absence of ligand conformers.



(a)

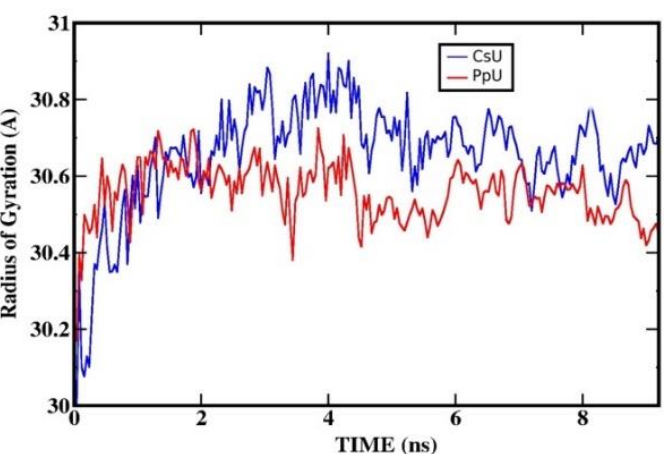

(b)

Figure 8. (a) Radius of Gyration as a function of time period of simulation for CsU protein and PpU protein with urea. (b) Radius of Gyration as a function of time period of simulation for CsU protein and PpU protein without urea.

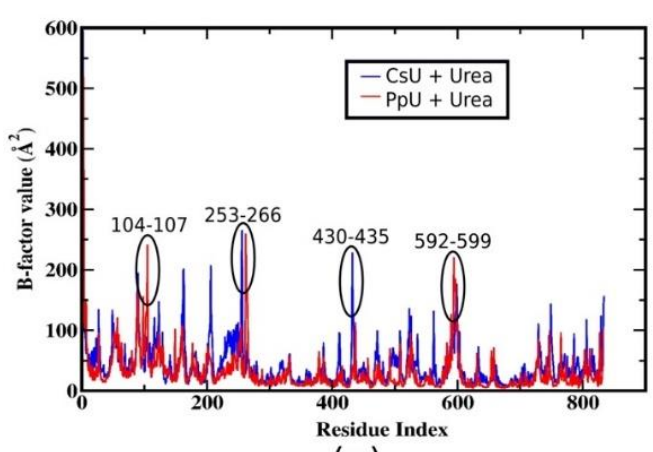

(a)

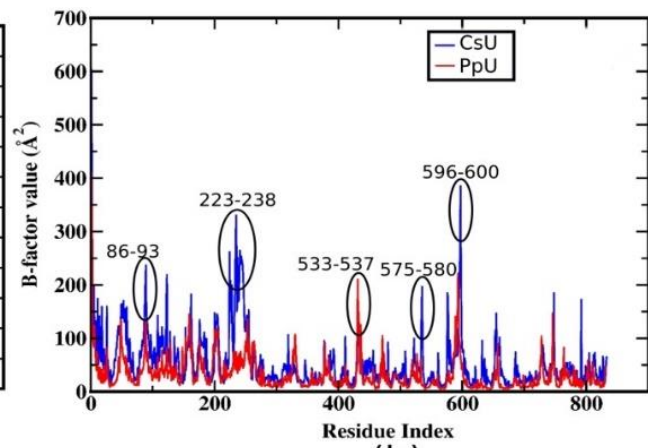

(b)

Figure 9. (a) B-Factor Value of $\mathrm{C} \alpha$ atoms as a function of amino acids for $\mathrm{CsU}$ protein and PpU protein with urea during $10 \mathrm{~ns}$ simulation. (b) B-Factor Value of $\mathrm{C} \alpha$ atoms as a function of amino acids for CsU protein and PpU protein without urea during 10 ns simulation.

\subsubsection{B-factor analysis.}

To determine the flexible and rigid regions in $\mathrm{PpU}$ and $\mathrm{CsU}$, the $\mathrm{B}$-factor analysis was carried out (Figure 9a \& b), which showed that the complexes exhibit nearly the same flexible character across the chain of amino acids residues. But in the absence of ligand, they exhibit more flexibility in some parts (Residue index: 75-100, 220-260, 600-610) of the protein chain of CsU. 
3.6.5. Binding free energy analysis using MM-GBSA/PBSA.

The free energy of binding for PpU/CsU-urea complexes was determined by different computational methods with varying degrees of accuracy and efficiency [45]. But as most of the methods are computationally expensive, MM-PBSA/GBSA method was selected, which provides reasonably accurate results at a comparatively low computational cost [46, 47]. Another advantage of this method is that it gives information about the various contributions to the free energy, such as the van der Waals, electrostatic, and solvation contributions. The details of the MM-GBSA/PBSA calculations were shown in Table 3. The averaged binding free energy ( $\Delta \mathrm{G}_{\text {bind }}$ ) results for the PpU/CsU-urea complexes were also observed. In Table 3, PBTOT and GBTOT indicate the total binding free energies using the PBSA and GBSA. The negative total binding free energies (PBTOT/GBTOT $=-11.05 /-9.73 \mathrm{Kcal} / \mathrm{mol}$ ) for PpU-urea complex and $(\mathrm{PBTOT} / \mathrm{GBTOT}=-13.43 /-13.91 \mathrm{Kcal} / \mathrm{mol}$ ) for $\mathrm{CsU}$-urea complex showed that both the complexes are favorable, but the CsU structure shows relatively more binding affinity towards the urea ligandin comparison to PpU structure.

Table 3. Binding free energy (BFE) analysis for the PpU-Urea and CsU-Urea has been done using MM-PBSA, MM-GBSA.

\begin{tabular}{l|l|l}
\multirow{2}{*}{ Components } & $\Delta G_{\text {bind }} \boldsymbol{P p U}-$ Urea & $\Delta G_{\text {bind }} \boldsymbol{C s} \boldsymbol{U}-$ Urea \\
\cline { 2 - 3 } & mean \pm std & mean \pm std \\
\hline ELE & $-11.77 \pm 4.14$ & $-22.07 \pm 7.18$ \\
\hline VDW & $-9.86 \pm 1.38$ & $-10.48 \pm 1.59$ \\
\hline INT & $0.00 \pm 0.00$ & $0.00 \pm 0.00$ \\
\hline GAS & $-21.64 \pm 3.78$ & $-32.55 \pm 6.71$ \\
\hline PBSUR & $-1.14 \pm 0.06$ & $-1.09 \pm 0.06$ \\
\hline PBCAL & $11.72 \pm 2.43$ & $20.22 \pm 3.79$ \\
\hline PBSOL & $10.58 \pm 2.43$ & $19.13 \pm 3.79$ \\
\hline PBELE & $-0.05 \pm 2.77$ & $-1.86 \pm 4.19$ \\
\hline PBTOT & $-11.05 \pm 2.42$ & $-13.43 \pm 3.60$ \\
\hline GBSUR & $-1.14 \pm 0.06$ & $-1.09 \pm 0.06$ \\
\hline GB & $13.04 \pm 2.34$ & $19.74 \pm 5.01$ \\
\hline GBSOL & $11.90 \pm 2.35$ & $18.65 \pm 5.03$ \\
\hline GBELE & $1.27 \pm 2.58$ & $-2.34 \pm 2.86$ \\
\hline GBTOT & $-9.73 \pm 2.29$ & $-13.91 \pm 2.37$
\end{tabular}

Note: All the units are $\mathrm{kcal}^{\mathrm{mol}}{ }^{-1}$. ELE: non-bonded electrostatic energy; VDW: non-bonded van der Waals energy; INT: bond, angle, dihedral energies; GAS: ELE + VDW + INT; PBSUR: hydrophobic contribution to solvation free energy for PB calculations; PBCAL: reaction field energy calculated by PB; PBSOL: PBSUR + PBCAL; PBELE: PBCAL + ELE; PBTOT: PBSOL + GAS;

GBSUR: hydrophobic contribution to solvation free energy for GB calculations; GB: reaction field energy calculated by GB; GBSOL: GBSUR + GB; GBELE: GB + ELE; GBTOT: GBSOL + GA

\section{Conclusions}

In this study, we report five mutation hot spots of the PpU crystal structure. We modeled the structure of two protein sequences ( $\mathrm{CsU}$ and $\mathrm{FvU}$ ) based on the mutation hotspots of $\mathrm{PpU}$ and found two urea binding sites in $\mathrm{PpU}$ by molecular phylogenetic and local alignment analysis. We identified the binding site located near the Arg163 of PpU as a high-affinity binding site for urea, and the same binding site was used for the docking analysis of other plant ureases, CsU and FvU. Among the three docked complexes, CsU-urea docked structure was observed to have a low binding energy value of $-3.37 \mathrm{kcal} / \mathrm{mol}$ as compared to PpU-urea -2.71 $\mathrm{kcal} / \mathrm{mol}$ and FvU-urea $-2.42 \mathrm{kcal} / \mathrm{mol}$. From the docking analysis and MM-GBSA/PBSA studies, it is reported that the $\mathrm{CsU}$ is a high-affinity urease. CsU-urease complex stability is further validated by MD simulation studies, and the results are compared with that of the PpU- 
urea complex. In conclusion, $\mathrm{CsU}$ was identified as a potential plant-based urea binding enzyme even though its crystal structure has not been resolved yet.

\title{
Funding
}

This research received no external funding.

\section{Acknowledgments}

\begin{abstract}
A.D.B. acknowledges Scuola Normale Superiore di Pisa and the University of L'Aquila for his doctoral scholarship. M.V.S.K. would like to thank the Tezpur University and University Grants Commission, India, for the start-up grant and DBT funded Bioinformatics Infrastructure facility in the Department of Molecular Biology and Biotechnology at Tezpur University for providing us computational facility to carry out this research work.
\end{abstract}

\section{Conflicts of Interest}

The authors declare no conflict of interest.

\section{References}

1. Sirko, A.; Brodzik, R. Plant ureases: roles and regulation. Acta. Biochim. Pol. 1999, 47, 1189-1195.

2. $\quad$ Chaves-Silva, S.; Horta. L.P.; Souza, L.T.; da Silva, C.M.; Dohanik, C.S.; Goulart, G.A.; Marriel, I.E.; de Fátima, Â.; Modolo, L.V. Do schiff bases-based urease inhibitors improve plant growth and affect the activity of soil arginase?. Ind. Crops Prod. 2020, 145, https://doi.org/10.1016/j.indcrop.2019.111995.

3. Arora, R.; Issar, U.; Kakkar, R. Identification of novel urease inhibitors: pharmacophore modeling, virtual screening and molecular docking studies. J. Biomol. Struct. Dyn. 2019, 37, 4312-26, https://doi.org/10.1080/07391102.2018.1546620

4. Rizvi, F.; Khan, M.; Jabeen, A.; Siddiqui, H.; Choudhary, M.I. Studies on isoniazid derivatives through a medicinal chemistry approach for the identification of new inhibitors of urease and inflammatory markers. Sci. Rep. 2019, 9, 1-4, https://doi.org/10.1038/s41598-019-43082-0.

5. Liu, X.; Ai, Y.; Zhang, F.; Lu, S.; Zeng, X.; Fan, M. Crop production, nitrogen recovery and water use efficiency in rice-wheat rotation as affected by non-flooded mulching cultivation (NFMC). Nutr. Cycl. Agroecosyst. 2005, 71, 289-299, https://doi.org/10.1007/s10705-004-6801-4.

6. Qiao, Y.; Yin, L.; Wang, B.; Ke, Q.; Deng, X.; Wang, S. Melatonin promotes plant growth by increasing nitrogen uptake and assimilation under nitrogen deficient condition in winter wheat. Plant Physiol. Biochem. 2019, 139, 342-9, https://doi.org/10.1016/j.plaphy.2019.03.037.

7. Follmer, C. Insights into the role and structure of plant ureases. Phytochemistry 2008, 69, 18-28, https://doi.org/10.1016/j.phytochem.2007.06.034

8. Liu, S.; Wang, X.; Yin, X.; Savoy, H.J.; McClure, A.; Essington, M.E. Ammonia Volatilization Loss and Corn Nitrogen Nutrition and Productivity with Efficiency Enhanced UAN and Urea under No-tillage. Sci. Rep. 2019, 9, 1-2, https://doi.org/10.1038/s41598-019-42912-5.

9. Sánchez-Luna, L.D.; Converti, A.; Tonini, G.C.; Sato, S.; de Carvalho, J. Continuous and pulse feedings of urea as a nitrogen source in fed-batch cultivation of Spirulina platensis. Aqua cultural engineering 2004, 31 , 237-245, https://doi.org/10.1016/j.aquaeng.2004.04.003.

10. Hu, H.; Deng, C.; Wang, X.; Chen, Z.; Zhong, Z.; Wang, R. Performance and mechanism of urea hydrolysis in partial nitritation system based on SBR. Chemosphere 2020, 258, https://doi.org/10.1016/j.chemosphere.2020.127228.

11. Bharadwaj, N.; Barthakur, S.; Biswas, A.D.; Das, M.K.; Kour, M.; Ramteke. A.; Gogoi. N. Transcript expression profiling in two contrasting cultivars and molecular cloning of a SKP-1 like gene, a component of SCF-ubiquitin proteasome system from mungbean Vigna radiate L. Sci. Rep. 2019, 9, 1-7, https://doi.org/10.1038/s41598-019-44034-4.

12. Sahney, R.; Anand, S.; Puri, B.K.; Srivastava, A.K. A comparative study of immobilization techniques for urease on glass-pH-electrode and its application in urea detection in blood serum. Analytica Chimica Acta 2006, 578, 156-161, https://doi.org/10.1016/j.aca.2006.06.063

13. Seifan, M.; Sarabadani, Z.; Berenjian, A. Development of an Innovative Urease-Aided Self-Healing Dental Composite. Catalysts 2020, 10, https://doi.org/10.3390/catal10010084. 
14. Altschul, S.F.; Madden, T.L.; Schaffer, A.A.; Zhang, J.; Zhang, Z.; Miller, W.; Lipman, D.J. Gapped BLAST and PSI-BLAST: a new generation of protein database search programs. Nucleic. Acids. Res. 1997, 25, 33893402, https://doi.org/10.1093/nar/25.17.3389.

15. Roy, A.; Kucukural, A.; Zhang, Y. I-TASSER: a unified platform for automated protein structure and function prediction. Nat. Protoc. 2010, 5, 725-738, https://doi.org/10.1038/nprot.2010.5.

16. Morris, G.M.; Huey, R.; Lindstrom, W.; Sanner, M.F.; Belew, R.K.; Goodsell, D.S.; Olson, A.J. Autodock4 and AutoDockTools4: automated docking with selective receptor flexiblity. J. Comput. Chem. 2009, 16, 2785-91.

17. Homeyer, N.; Gohlke, H. Free energy calculations by the Molecular Mechanics Poisson-Boltzmann Surface Area method. Mol. Inform. 2012, 31, 114-122, https://doi.org/10.1002/minf.201100135

18. Balasubramanian, A.; Durairajpandian, V.; Elumalai, S.; Mathivanan, N.; Munirajan, A.K.; Ponnuraj, K. Structural and functional studies on urease from Pigeon pea (Cajanus Cajan). Int. J. Biol. Macromol. 2013, 58, 301-309, https://doi.org/10.1016/j.ijbiomac.2013.04.055.

19. Pavelka, A.; Chovancova, E.; Damborsky, J. HotSpot Wizard: a web server for identification of hot spots in protein engineering. Nucleic. Acids. Res. 2009, 37, W376-W383, https://doi.org/10.1093/nar/gkp410.

20. Porter, C.T.; Bartlett, G.J.; Thornton, J.M. The Catalytic Site Atlas: a resource of catalytic sites and residues identified in enzymes using structural data. Nucleic. Acids. Res. 2004, 32, D129-D133, https://doi.org/10.1093/nar/gkh028.

21. Sievers, F.; Wilm, A.; Dineen, D.; Gibson, T.J.; Karplus, K.; Li,W.; Higgins, D.G. Fast scalable generation of high-quality protein multiple sequence alignments using Clustal Omega. Mol. Syst. Biol. 2011, 7, https://doi.org/10.1038/msb.2011.75.

22. Zhang, Y. I-TASSER server for protein 3D structure prediction. BMC bioinformatics 20089 , https://doi.org/10.1186/1471-2105-9-40.

23. Laskowski, R.A.; MacArthur, M.W.; Moss, D.S.; Thornton, J.M. PROCHECK: a program to check the stereo chemical quality of protein structures. J. Appl. Cryst. 1993, 26, 283-291, https://doi.org/10.1107/S0021889892009944.

24. Berman, H.M.; Westbrook, J.; Feng, Z.; Gilliland, G.; Bhat, T.N.; Weissig, H.; Bourne, P.E. The protein data bank. Nucleic. Acids. Res. 2000, 28, 235-242, https://doi.org/10.1093/nar/28.1.235

25. Goujon, M.; McWilliam H.; Li, W.; Valentin, F; Squizzato, S; Paern, J; Pez, R. A new bioinformatics analysis tools framework at EMBL-EBI. Nucleic. Acids. Res. 2010, 38, W695-W699, https://doi.org/10.1093/nar/gkq313.

26. Wallace, A.C.; Laskowski, R.A.; Thornton, J.M. LIGPLOT: a program to generate schematic diagrams of protein-ligand interactions. Protein Eng. 1995, 8, 127-134, https://doi.org/10.1093/protein/8.2.127.

27. Goujon, M.; McWilliam, H.; Li, W.; Valentin, F.; Squizzato, S.; Paern, J.; Lopez, R. A new bioinformatics analysis tools framework at EMBL-EBI. Nucleic. Acids. Res. 2010, 38, W695-W699, https://doi.org/10.1093/nar/gkq313.

28. Huey, R.; Morris, G.M. Using AutoDock 4 with Auto Dock Tools: A Tutorial. The Scripps Research Institute 2008.

29. Meng, E.C.; Pettersen, E.F.; Couch, G.S.; Huang, C.C.; Ferrin, T.E. Tools for integrated sequence-structure analysis with UCSF Chimera. BMC. bioinformatics. 2006, 7, https://doi.org/10.1186/1471-2105-7-339.

30. Saitou, N.; Nei, M. The neighbor-joining method: a new method for reconstructing phylogenetic trees. Mol. Biol. Evol. 1987, 4, 406-425, https://doi.org/10.1093/oxfordjournals.molbev.a040454.

31. Radwan, A.; Khalid, M.; Amer, H.; Alotaibi, M. Anticancer and molecular docking studies of some new pyrazole-1-carbothioamide nucleosides. Biointerface Res. Appl. Chem. 2019, 9, 4640-4648, https:///doi.org/10.33263/BRIAC96.642648.

32. Fatonah, A.; Tambunan, U.S.F.; Pamungkas, W.O.; Dewanto, G.L.; Wicaksono, I.S. Discovery of GPX4 inhibitor by molecular docking simulation as a potential ferroptosis inducer. Biointerface Res. Appl. Chem. 2020, 10, 4929-4933, https://doi.org/10.33263/BRIAC101.929933.

33. Sanner, M.F. Python: a programming language for software integration and development. J. Mol. Graph. Model 1999, 17, 57-61.

34. Cornell, W.D.; Cieplak, P.; Bayly, C.I.; Gould, I.R.; Merz, K.M.; Ferguson, D.M.; Kollman, P.A. A second generation force field for the simulation of proteins, nucleic acids, and organic molecules. Am. Chem. Soc. 1995, 17, 5179-5197, https://doi.org/10.1021/ja00124a002.

35. Tsui, V.; Case, D.A. Theory and applications of the generalized Born solvation model in macromolecular simulations. Biopolymers 2000, 56, 275-91, https://doi.org/10.1002/1097-0282(2000)56:4<275::AIDBIP10024>3.0.CO;2-E.

36. Pearlman, D.A.; Case, D.A.; Caldwell, J.W.; Ross, W.S.; Cheatham III, T.E.; DeBolt, S.; Kollman, P. AMBER, a package of computer programs for applying molecular mechanics, normal mode analysis, molecular dynamics and free energy calculations to simulate the structural and energetic properties of molecules. Comput. Phys. Commun. 1995, 91, 1-41, https://doi.org/10.1016/0010-4655(95)00041-D.

37. Hornak, V.; Abel, R.; Okur, A.; Strockbine, B.; Roitberg, A.; Simmerling, C. Comparison of multiple Amber force fields and development of improved protein backbone parameters. Proteins: Struct., Funct., Bioinf. 2006, 65, 712-725, https://doi.org/10.1002/prot.21123 
38. Jorgensen, W.L.; Chandrasekhar, J.; Madura J.D.; Impey, R.W.; Klein, M.L. Comparison of simple potential functions for simulating liquid water. J Chem Phys 1983, 79, https://doi.org/10.1063/1.445869.

39. Ryckaert, J.P.; Ciccotti,G.; Berendsen, H.J.C. Numerical-Integration of Cartesian equations of motion of a system with constraints - molecular-dynamics of N-Alkanes. J. Chem. Phys. 1977, 23, 327-341, https://doi.org/10.1016/0021-9991(77)90098-5.

40. Berendsen, H.J.; Postma, J.P.M.; van Gunsteren, W.F.; DiNola, A.R.H.J.; Haak, J.R. Molecular dynamics with coupling to an external bath. J. Chem. Phys. 1984, 81, https://doi.org/10.1063/1.448118

41. Pettersen, E.F.; Goddard, T.D.; Huang, C.C.; Couch, G.S.; Greenblatt, D.M.; Meng, E.C.; Ferrin, T.E. UCSF Chimera-a visualization system for exploratory research and analysis. J. Comput. Chem. 2004, 25, 16051612.

42. Cherry, J.R.; Fidantsef, A.L. Directed evolution of industrial enzymes: an update. Curr. Opin. Biotechnol. 2003, 14, 438-443, https://doi.org/10.1016/S0958-1669(03)00099-5.

43. Kimura, M. A simple method for estimating evolutionary rates of base substitutions through comparative studies of nucleotide sequences. J. Mol. Evol. 1980, 16, 111-120, https://doi.org/10.1007/BF01731581

44. McWilliam, H.; Li, W.; Uludag, M.; Squizzato, S.; Park, Y.M.; Buso, N.; Lopez, R. Analysis tool web services from the EMBL-EBI. Nucleic. Acids. Res. 2013, 41, W597-W600, https://doi.org/10.1093/nar/gkt376.

45. Chipot, C.; Pohorille, A. Free energy calculations. $1^{\text {st }}$ Edition.; Chipot, C.; Pohorille, A. Springer Berlin, Springer-Verlag Berlin Heidelberg, Germany, 87, XVIII, 2007; pp. 518, https://doi.org/10.1007/978-3-54038448-9_2

46. Hou, T.; Wang, J.; Li, Y.; Wang, W. Assessing the performance of the MM/PBSA and MM/GBSA methods: I. The accuracy of binding free energy calculations based on molecular dynamics simulations. J. Chem. Inf. Model. 2011, 51, 69-82, https://doi.org/10.1021/ci100275a.

47. Wang, E.; Weng, G.; Sun, H.; Du, H.; Zhu, F.; Chen, F.; ... \& Hou, T. Assessing the performance of the $\mathrm{MM} / \mathrm{PBSA}$ and MM/GBSA methods. 10. Impacts of enhanced sampling and variable dielectric model on protein-protein Interactions. Phys. Chem. Chem. Phys., 2019,21(35), 18958-18969, https://doi.org/10.1039/C9CP04096J. 


\section{Supplementary files}
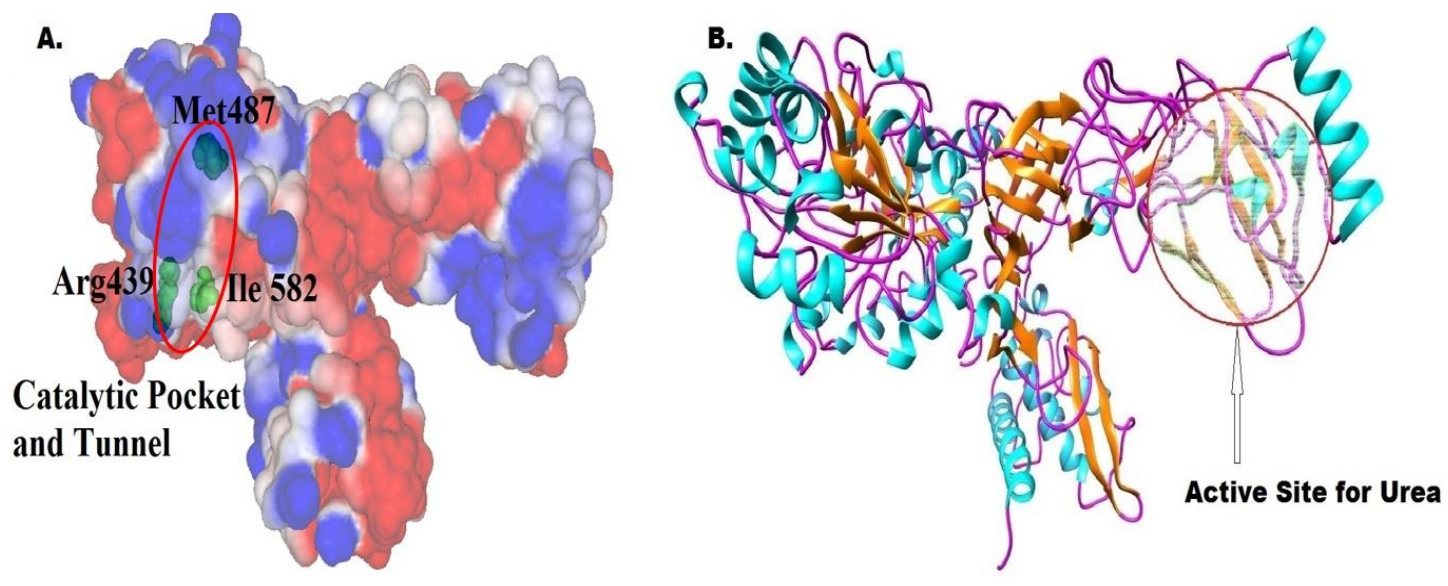

Figure S1. A.) The Catalytic pocket and the tunnel is shown on the surface of PPU. B.) Secondary structure analysis of PPU (color-coding according to secondary structures).

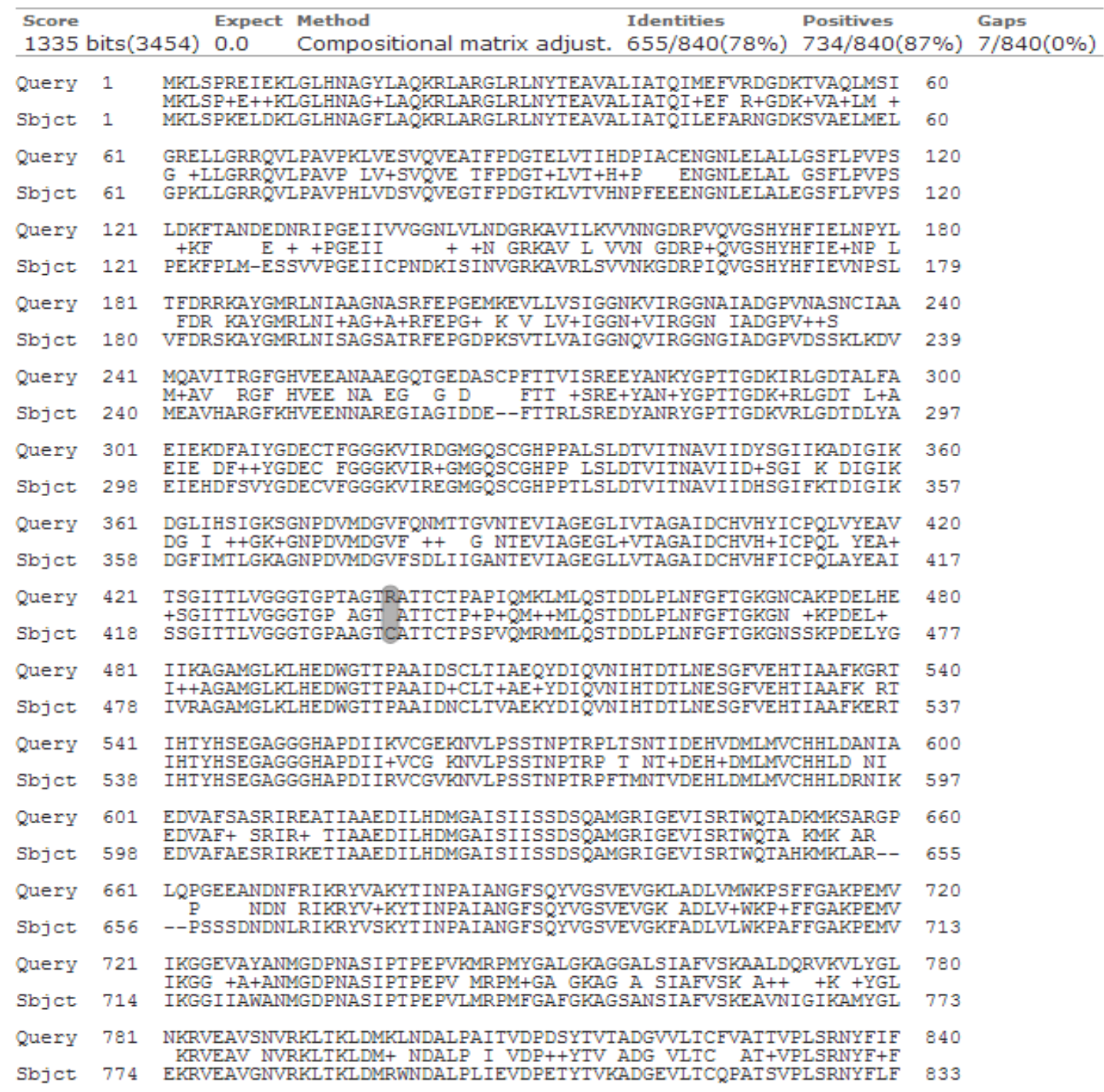

Figure S2. Alignment of pigeon pea urease sequence with Cucumis sativus urease sequence- Two residue belonging to the mutation sites of PPU, are shaded grey. The mutation sites were predicted by HOTSPOT server. For Arg439 of PPU there is Cys in CSU. 


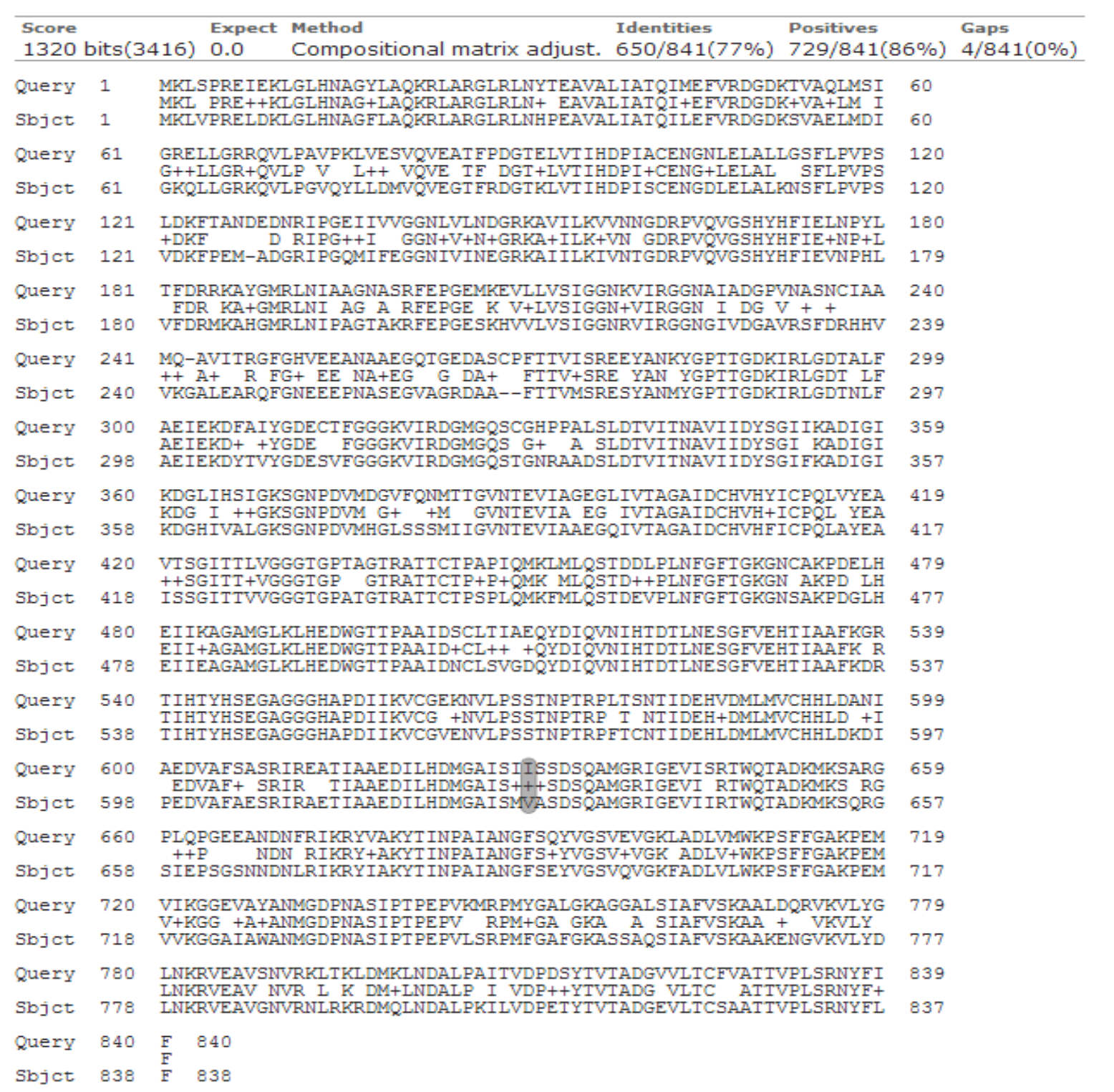

Figure S3. Alignment of pigeon pea urease sequence with Fragaria vesca urease sequence- One residue belonging to a mutation site of PPU, is shaded grey. The mutation sites were predicted by HOTSPOT server. For Ile of PPU at 630 there is Val in FVU.

A)



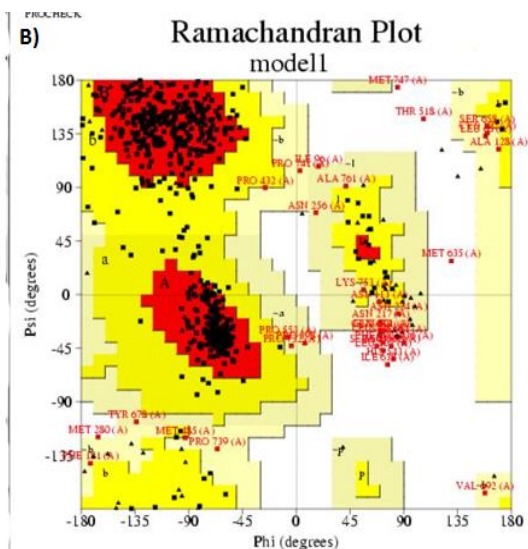

Figure S4. Structural and geometrical analysis of the Fragaria vesca urease- A) Secondary structure analysis (color-coding according to secondary structures) B) Ramachandran plot showing allowed dihedral $(\psi$ and $\phi)$ angles and A, B, L shows most favored with $87.2 \%$ of the residues, additionally favored (a, b, $1, \mathrm{p})$ with $6.9 \%$ of the residues and generously allowed $(\sim \mathrm{a}, \sim \mathrm{b}, \sim 1, \sim \mathrm{p})$ regions having $5.9 \%$ of the residues. Triangles represents Glycine residue. 
A)

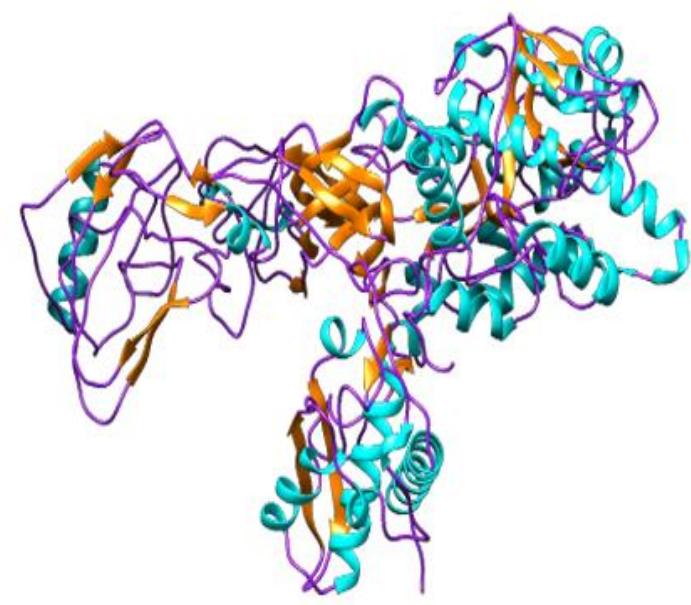

B) Ramachandran Plot

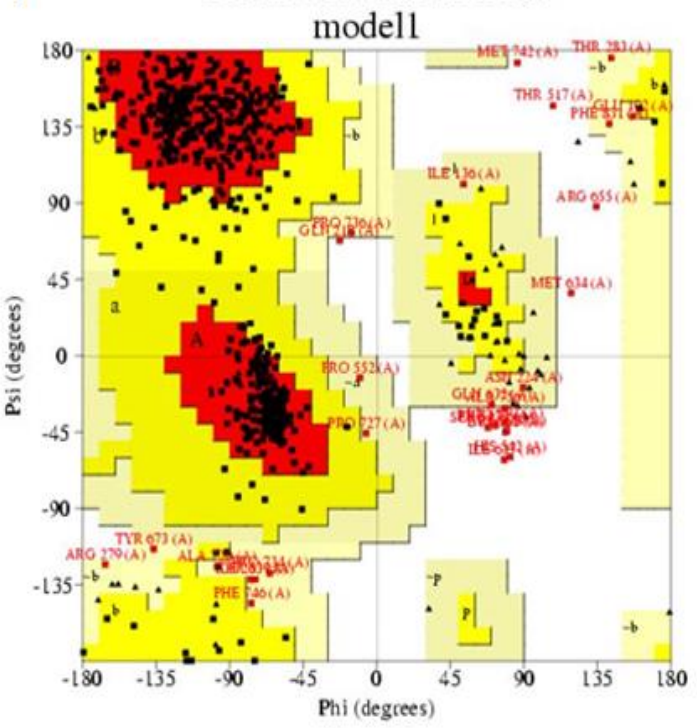

Figure S5. Structural and geometrical analysis of the Cucumis sativus urease - A.) Secondary structure analysis (colour - coding according to secondary structures) B.) Ramachandran plot showing allowed dihedral $(\psi$ and $\phi)$ angles and A, B, L shows most favoured with $89.3 \%$ of the residues, additionally favoured (a, b, 1, p) with 6.7 $\%$ of the residues and generously allowed $(\sim \mathrm{a}, \sim \mathrm{b}, \sim 1, \sim \mathrm{p})$ regions having $4.0 \%$ of the residues. Triangles represents Glycine residue.

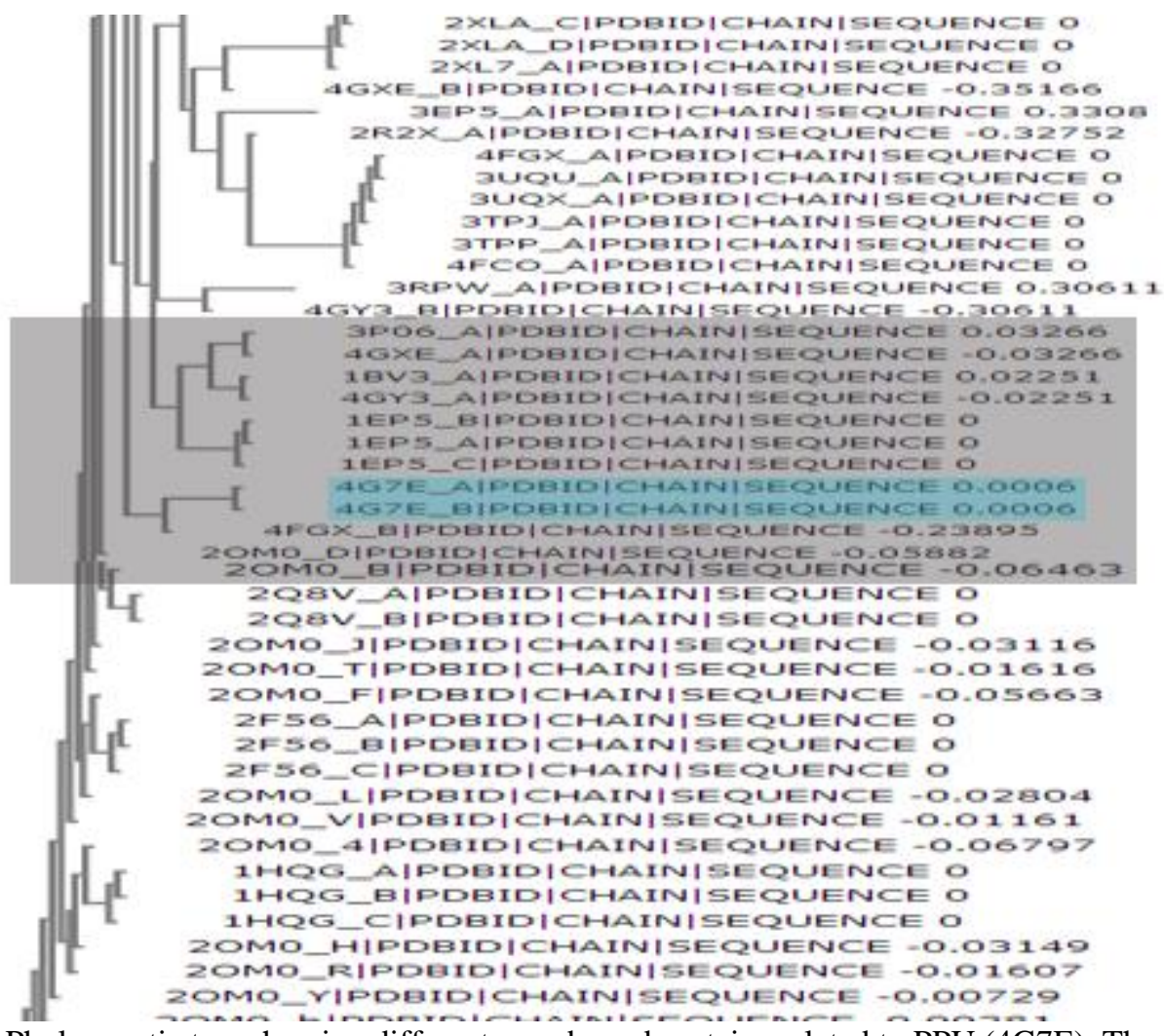

Figure S6. Phylogenetic tree showing different urea-bound proteins related to PPU (4G7E). The proteins with less distance to PPU (4G7E) were chosen for further binding site analysis of PPU. 
A)

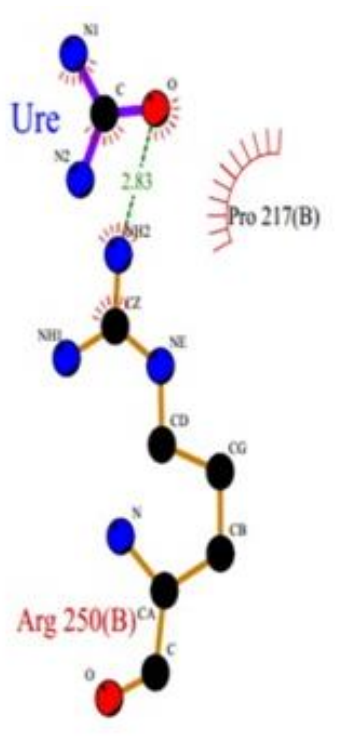

B)

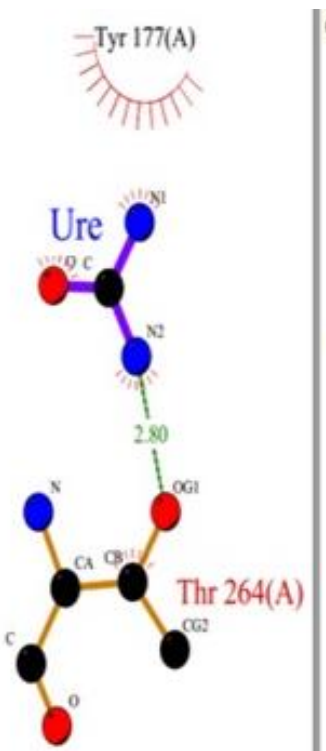

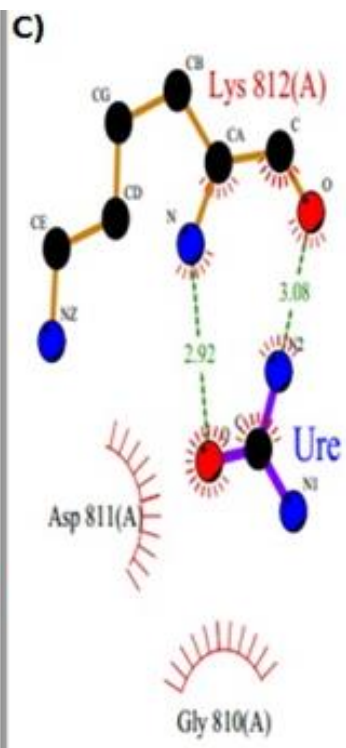

Figure S7. LIGPLOT's showing the interacting residues of protein molecule with urea- A) Interaction of urea with chain B of Capsid protein C (1EP5_B), Arg250 is forming hydrogen bond and Pro217 has hydrophobic contact with urea. B) With chain A of Capsid protein C (1EP5_A), Thr264 is forming hydrogen bonding and Tyr177 has hydrophobic contact with urea. C) With VP4 protein (3P06_A), Lys812 is forming hydrogen bonding and Gly810 \& Asp811 have hydrophobic contacts with urea.

Table S1. Amino acids involved in hydrogen bonding and hydrophobic contacts of closely related proteins with respect to PPU for urea ligand by the help of LIGPLOT (PDBSum).

\begin{tabular}{c|c|c|c} 
PDB ID & Chain & Hydrogen Bonds(with Urea) & Hydrophobic Contacts(with Urea) \\
\hline 3P06 & A & A: Lys812 & A: Asp811, A: Gly810 \\
\hline 1EP5 & A & A: Thr264 & A: Tyr177 \\
\hline 1EP5 & B & B: Arg250 & B: Pro217
\end{tabular}

